\title{
Ocular ultrastructural study in a fetus with type II glycogenosis
}

\author{
J. LIBERT, ${ }^{1}$ J.-J. MARTIN, ${ }^{2}$ C. CEUTERICK, ${ }^{2}$ AND P. DANIS ${ }^{1}$ \\ From the Department of Ophthalmology, Free University of Brussels, ${ }^{1}$ and the Department of \\ Neuropathology, Born-Bunge Foundation and Antwerp University Medical School ${ }^{2}$
}

SUMMARY The general pathological and ocular studies in an aborted fetus with type II glycogenosis revealed the widespread lysosomal storage of glycogen. Obvious lesions are observed in the viscera, in the skeletal and ocular muscles, and in all ocular tissues except the pigment epithelium of the retina. Brain and heart are relatively spared. Conjunctival and skin biopsies have a diagnostic importance, since specific alterations are evident early in the course of the disease.

Type II glycogenosis, an autosomal recessive disorder, is characterised by a lack of $\alpha$-1,4-glucosidase (acid maltase) (Hers, 1963) resulting in the lysosomal storage of glycogen in various tissues (Baudhuin et al., 1964). The muscles are mainly involved, and their abnormal contractile functions explain the symptoms of hypotonia, respiratory insufficiency, cardiomegaly, and cardiac failure leading to death within the first 2 years of life in the classical infantile form (Pompe disease). Glycogen storage has also been demonstrated in the liver, the kidney, the skin, and the nervous system in these cases (Hers and de Barsy, 1973). Less severe phenotypes have been reported, with childhood and adult onset (Engel et al., 1973).

The disorder can be detected in utero by the enzymatic study of cultured amniotic cells. Subsequent therapeutic abortion permitted the investigation of the early biochemical and histopathological changes (Hug et al., 1973; Nadler and Messina, 1969; Schaub et al., 1974).

Toussaint and Danis (1965) observed by light microscopy the widespread storage of glycogen in the eyes of an infant with Pompe disease. Ultrastructural changes of the ocular muscles have been studied by Smith and Reinecke (1972), but the ocular lesions have not, to our knowledge, been reported by electron microscopy.

The purpose of this paper is to describe the lysosomal storage of glycogen in most of the ocular tissues in an aborted fetus with acid maltase deficiency. The presence of abnormal glycogen deposits

Address for reprints: Dr J. Libert, Clinique Ophtalmologique, Hôpital Universitaire Saint-Pierre, Université Libre de Bruxelles, Rue Haute 322, B-1000 Bruxelles, Belgium within the conjunctival cells is important for the diagnosis of the disease by conjunctival biopsy, which was demonstrated in an unrelated case.

\section{Case reports}

CASE 1

This female fetus resulted from the fourth pregnancy of unrelated parents. Their first child died at 2 days of age because of oesophageal atresia. Their second child, a boy, presented a type II glycogenosis with prolonged survival to the age of 4 years 4 months. Pathological and biochemical findings have been previously reported (Martin et al., 1976). Their third pregnancy ended with a spontaneous abortion, but the fetus was biochemically unaffected, with normal $\alpha$-1,4-glucosidase activity.

During the 15th week of the fourth gestation a diagnostic amniocentesis was performed. Alpha1,4-glucosidase activity was reduced to $1 \%$ of the normal range in the cultured amniotic cells. At the parents' request a therapeutic abortion utilising prostaglandin was performed at 22 weeks of gestation.

CASE 2

This male infant, the first child of unrelated parents, was admitted to hospital at the age of $3 \frac{1}{2}$ months because of muscular weakness, respiratory insufficiency, and heart failure. The diagnosis of classical infantile Pompe disease was based on the clinical picture and on enzymatic, biochemical, and histopathological studies of a muscle biopsy ( $\mathrm{Dr}$ de Barsy). A conjunctival biopsy was performed at the age of 4 months. At this time the eyes were clinically normal. 


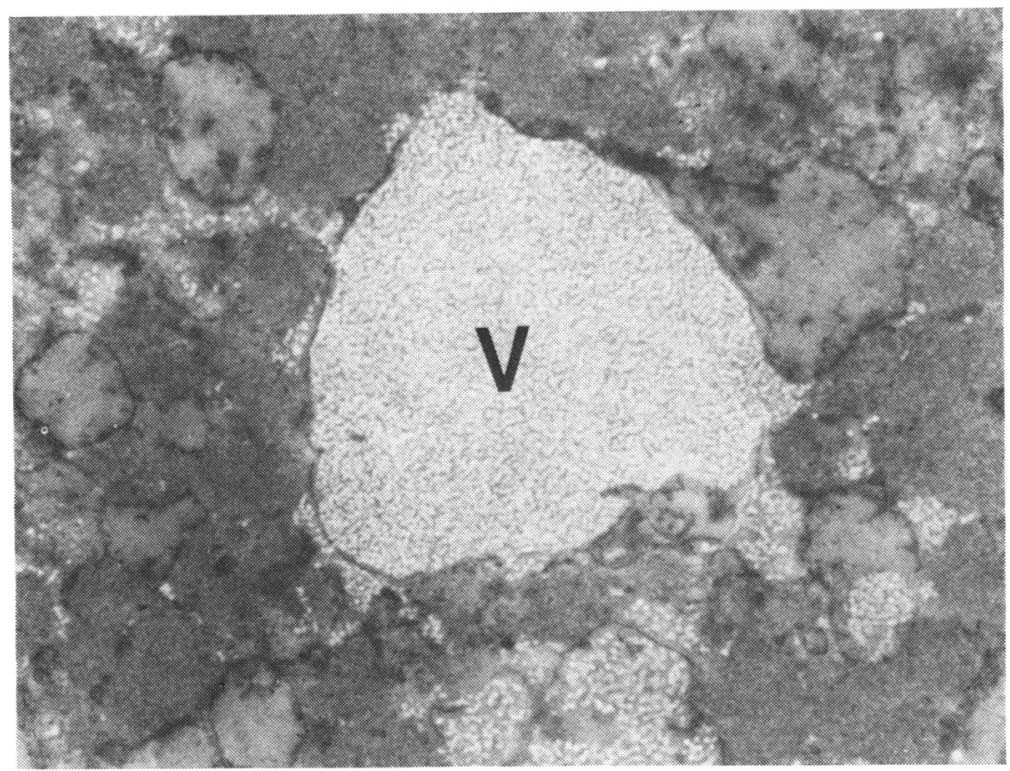

Fig. 1 Biceps femoris muscle. $A$ large membrane-bound glycogen vacuole $(V)$ occupies the centre of a muscle fibre (uranyl acetate, lead citrate. $\times 15000$ )

\section{Material and methods}

The fetal tissues were obtained within 1 hour of abortion. The eyes, the nervous system, the visceral organs, and the skeletal muscles were fixed and processed for light and electron microscopy according to previously reported methods (Libert et al., 1975; Martin et al., 1973). The conjunctival biopsy of the second case was obtained under topical anaesthesia from the upper bulbar conjunctiva and prepared for electron microscopy by the same technique. After orientation of the specimens on semithin sections, ultrathin sections were cut with a diamond knife on a Reichert OmU 2 microtome, stained with uranyl acetate and lead citrate (Reynolds, 1963) or with silver proteinate after periodic acid oxidation (Thiéry, 1967), and observed with a Philips EM300 electron microscope. Compari-

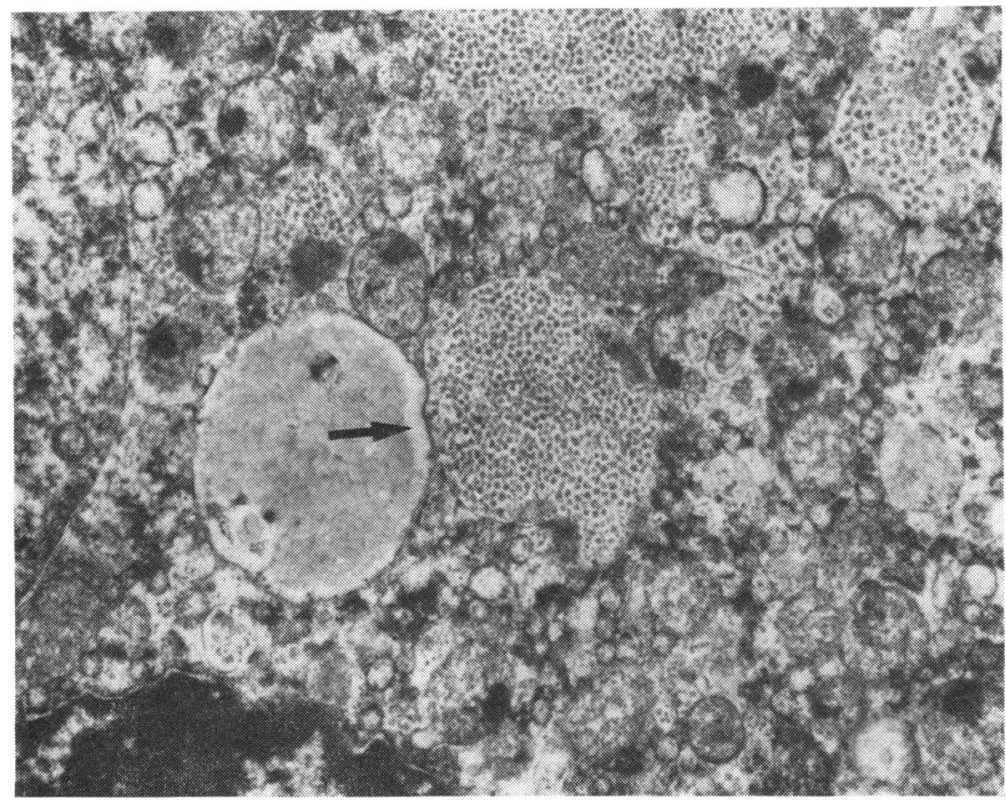

Fig. 2 Liver. Numerous glycogen-filled vacuoles (arrow) are present in a hepatocyte (uranyl acetate, lead citrate. $\times 15000)$ 
son was made with 3 normal fetuses aborted at similar gestation ages.

\section{Results}

AFFECTED FETUS

(a) General pathological examination (case 1): Lysosomal storage of glycogen was demonstrated

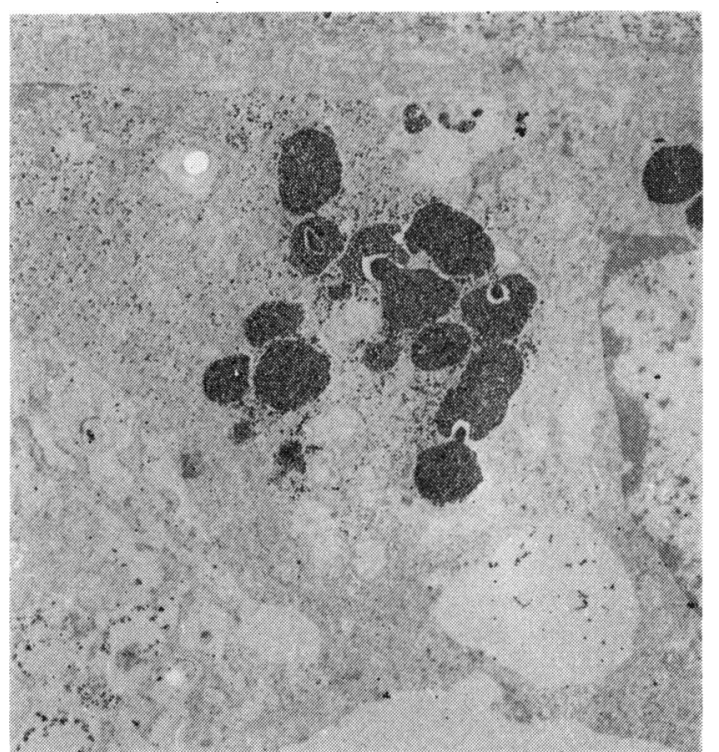

Fig. 3 Cornea. The corneal endothelial cells contain free glycogen granules and storage lysosomes, which are markedly stained with silver (silver proteinate. $\times 10000$ ) both by histochemical and by ultrastructural methods in four different skeletal muscles (Fig. 1) (quadriceps, triceps suralis, biceps femoris, and biceps brachii), in the liver (Fig. 2), in the skin (fibroblasts, endothelial cells, Schwann cells), in the peripheral nerves (Schwann cells of myelinated and unmyelinated axons), and in the kidneys (distal convoluted tubules). The heart and central nervous system were relatively spared: a few glycogen inclusions were found in myocardial fibres and in neurons of the anterior horns and of the mesencephalic root of the trigeminal nerve. The other neuronal groups were devoid of any glycogen storage. Only the ganglion cells of the spinal ganglia were loaded with glycogen.

(b) Ocular examination: Glycogen could be identified by light microscopy in the corneal epithelium and endothelium, in the lens epithelium, in the ciliary epithelium, and in the endothelium of the capillaries. The fetal retina seemed to be normal, though immature as in controls. The fibres of the oculomotor muscles contained many glycogen granules, but the general architecture was apparently conserved. These granules did not appear in salivary amylase-treated preparations.

In addition to confirming the lesions observed by light microscopy the ultrastructural studies demonstrated a more generalised storage process. Almost all examined cells displayed 0.2 to $1.5 \mu \mathrm{m}$ membranebound inclusions, which contained innumerable small glycogen particles, moderately contrasted by routine techniques, and markedly stained by silver proteinate.

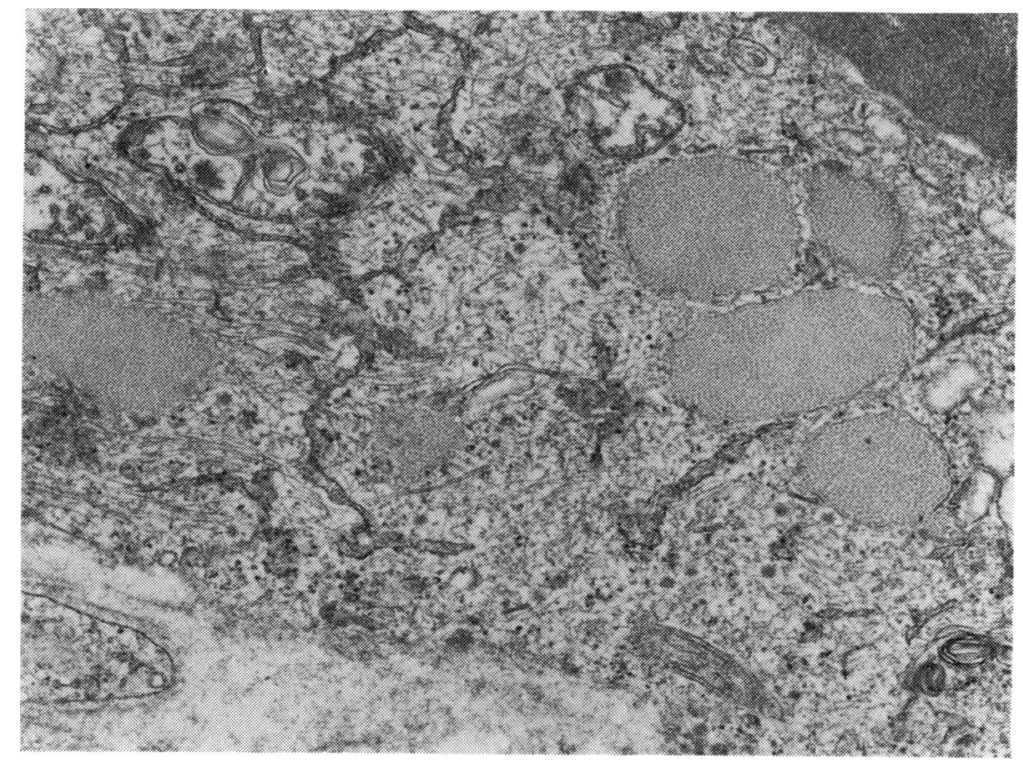

Fig. 4 Choroid. Several glycogen engorged inclusions are evident in the endothelial cell of a choroidal capillary (uranyl acetate, lead citrate. $\times 22000$ ) 


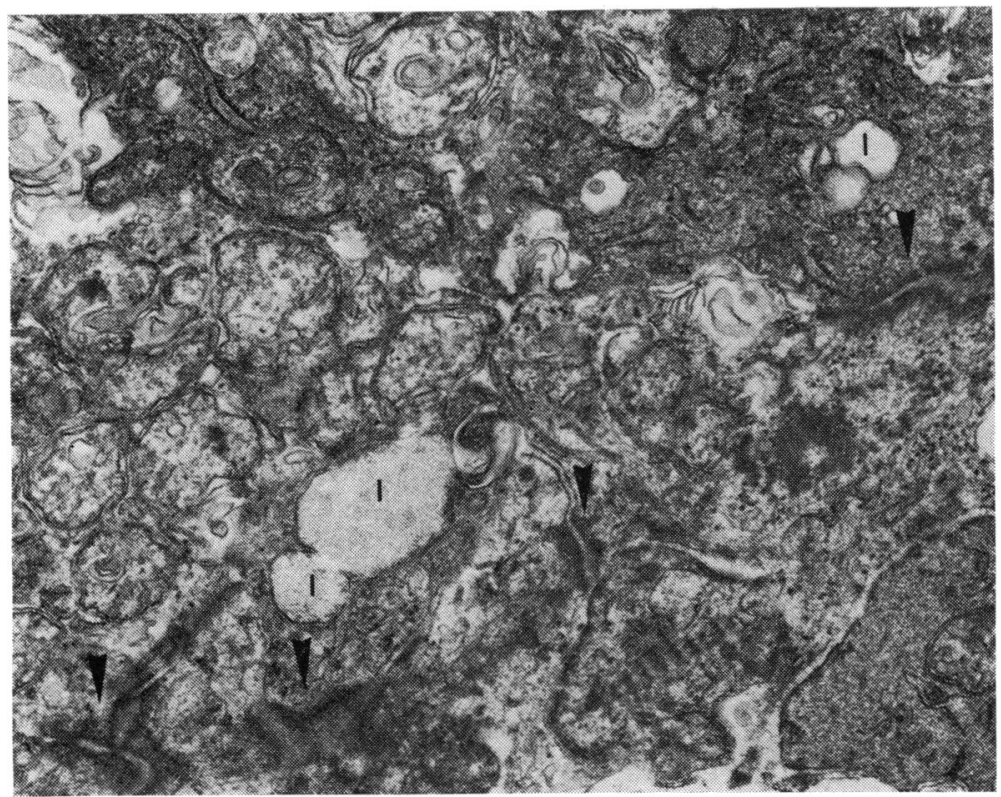

Fig. 5 Retina. The immature photoreceptors contain some inclusions (I). The mitochondria are particularly numerous in this portion of the cell, near the external limiting membrane (arrows) (uranyl acetate, lead citrate. $\times 25000)$

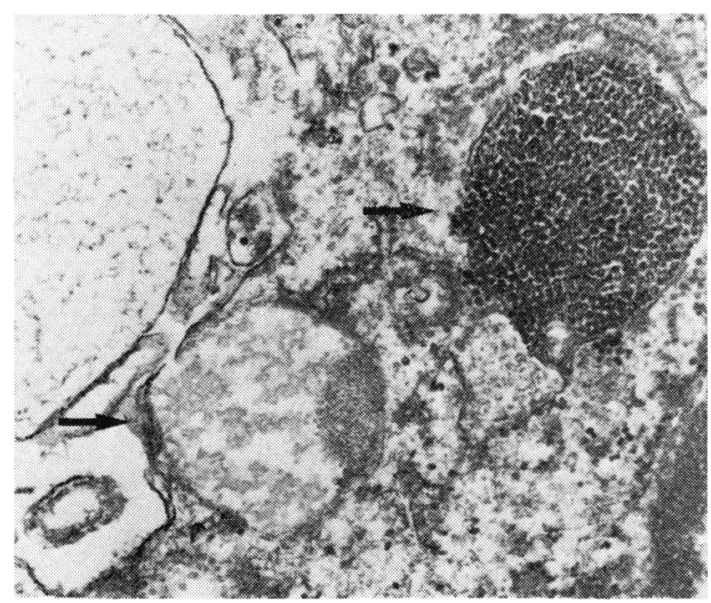

Fig. 6 Optic nerve. The lysosomal glycogen (arrows) can be more or less contrasted by the routine staining technique in the same structure or even in the same cell, as in this glial cell (uranyl acetate, lead citrate. $\times 34000$ )

These inclusions were observed in the conjunctival and corneal epithelial cells, in the keratocytes, the sclerocytes, the corneal endothelial cells (Fig. 3), the fibroblasts of the conjunctiva, iris, and the choroid, in the capillary endothelial cells of the conjunctiva, the uvea, and the retina (Fig. 4), in the ganglion cells, the Müller cells, and the photoreceptors (Fig. 5). The glial cells of the optic nerve were also involved (Fig. 6). In contrast, the retinal pigment epithelium was unaffected.
The fibres of the extrinsic ocular muscles contained a variable number of storage inclusions. They were sometimes packed closely together and displayed a marked tendency to confluence (Fig. 7). Their dimensions varied from 0.2 to $5 \mu \mathrm{m}$. Some fibres were much disorganised, stuffed with membranebound vacuoles and large areas of apparently free glycogen deposits in which disrupted membrane residues were recognisable.

\section{CONTROL FETUS}

Isolated glycogen granules were observed in the ocular fetal cells. These particles were particularly numerous in the corneal endothelium, but they were lying free in the cytoplasm and never included within a unit membrane.

\section{CONJUNCTIVAL BIOPSY}

In the conjunctival biopsy of case 2 at 4 months of age the glycogen inclusions had the same ultrastructural aspect and dimension as in the fetal eyes, but they were much more numerous. The epithelial cells, the fibroblasts (Fig. 8), and the blood capillary endothelial cells were considerably distended by the storage vacuoles. The Schwann cells of the sensory nerves were also involved, while the axons and the myelin sheaths were normal.

\section{Discussion}

Alpha-1,4-glucosidase deficiency was demonstrated on cultured amniotic cells of a high-risk pregnancy 


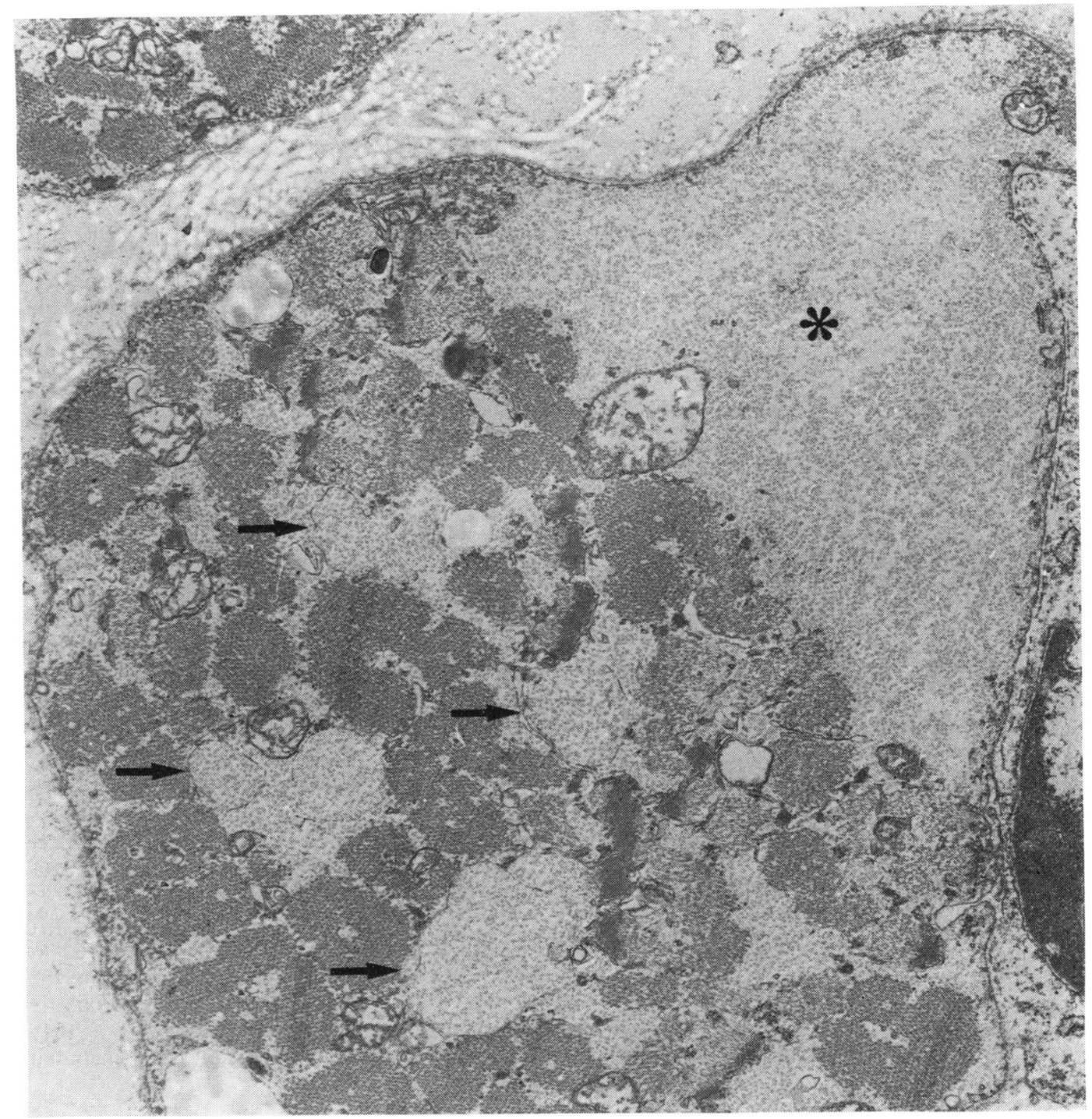

Fig. 7 Ocular muscles. The lysosomes (arrows) show a marked tendency to confluence and sometimes occupy large areas of the cytoplasm (asterisk) (uranyl acetate, lead citrate. $\times 16000$ )

and resulted in the therapeutic abortion of a fetus with type II glycogenosis. This biochemical technique is now widely used for the prenatal diagnosis of lysosomal diseases and allowed histopathological and biochemical analysis of affected fetal tissues (Adachi et al., 1974; Schneider et al., 1972), including the eyes (Howes et al., 1975). In our case these investigations indicated the early lysosomal storage of glycogen in skeletal muscles, liver, Schwann cells of peripheral nerves, skin, kidney, and to a much less extent in heart and central nervous system, strictly paralleling, although at a much earlier age, our previous findings in the affected sibling thought to represent a childhood phenotype rather than a classical example of Pompe disease (Martin et al., 1976). It can be hypothesised that the relative sparing of heart and central nervous system accounted for the prolonged survival of the index case.

Although no ocular abnormalities except strabismus (Smith and Reinecke, 1972) have been reported clinically, the eyes are markedly involved in type II glycogenosis. Toussaint and Danis (1965) demonstrated on necropsy material the accumulation of glycogen in the mural cells of the retinal capillaries, 


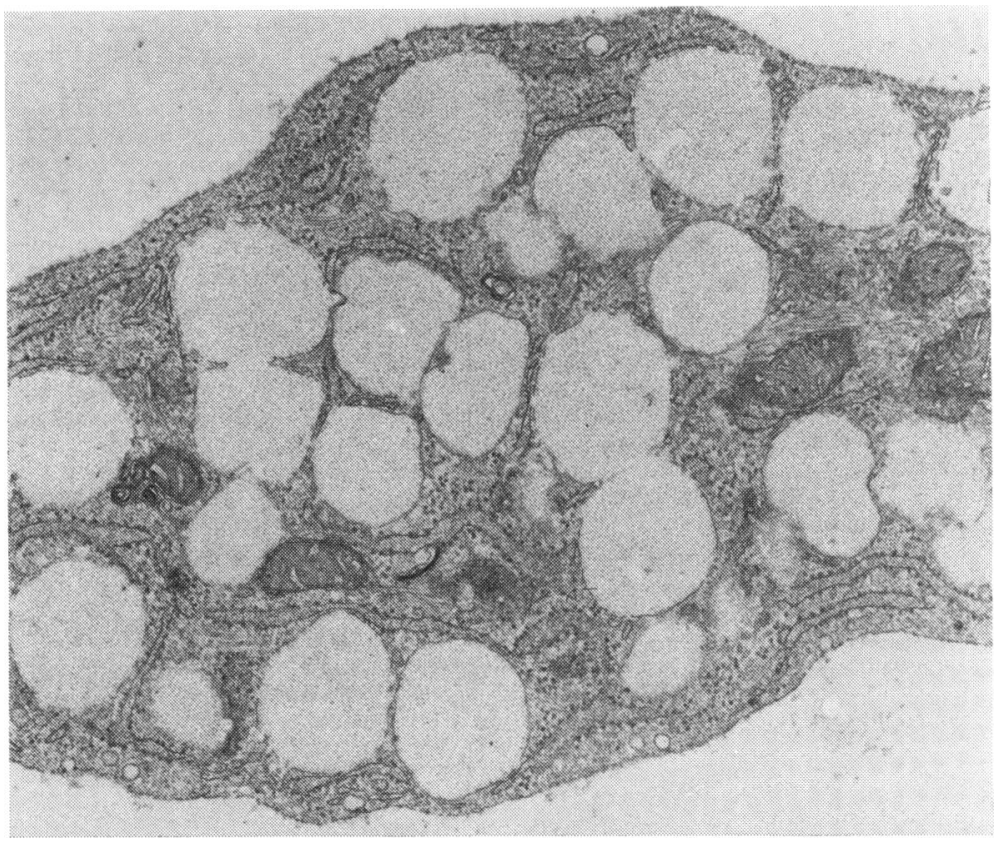

Fig. 8 Conjunctiva. The fibroblasts of this conjunctival biopsy of case 2 display numerous and characteristic glycogenengorged inclusions (uranyl acetate, lead citrate. $\times 28000$ )

in the ganglion cells, and in the smooth and striated muscle fibres of the eyes. Our light microscopic studies of an aborted fetus also suggest a widespread storage process. However, this might be a false conclusion because the fetal eye tissues are physiologically rich in glycogen, as shown in the controls.

Electron microscopy demonstrates clearly the generalised lesions. All ocular cell types, except the pigment epithelium of the retina, display membranebound inclusions which contain innumerable granules packed close together. The ultrastructural aspect of the inclusions and their staining properties with silver proteinate are characteristic of glycogenengorged lysosomes, while the glycogen particles of the control fetal cells lie free and disseminated in the cytoplasm, and the lysosomes have the normal appearance of very small dense bodies.

The storage is much more important in the oculomotor muscles, in which the inclusions reach enormous size and sometimes disorganise the general architecture of the cells. Extensive areas of free glycogen particles containing residual membrane fragments suggest mechanical rupture of the distended lysosomes. However, it seems impossible to determine whether it was the result of an ante- or post-mortem process. These findings are consistent with ultrastructural studies on muscle biopsy and necropsy specimens in the brother of the present case (Martin et al., 1976) and in other reported patients (Engel et al., 1973; Martin et al., 1973).

Smith and Reinecke (1972) examined by electron microscopy the inferior oblique muscle of a patient with type II glycogenosis. The tissues appeared less severely involved with deposits of free glycogen in generally well preserved muscle fibres, but the case seemed to belong to a milder clinical phenotype.

In case 2 the presence of many glycogen-engorged lysosomes in the conjunctival epithelial cells, fibroblasts, and capillary endothelial cells confirmed the diagnosis of type II glycogenosis by conjunctival biopsy. Skin biopsy also showed specific alterations in this disease (Martin et al., 1976). These morphological diagnoses are certainly possible just after birth, as the tissues are already affected in the fetus.

Dr J. G. Leroy, head of the laboratory of medical genetics, Antwerp University Medical School, referred the fetus to us. He and Dr W. Den Tandt, in this laboratory, performed the enzymatic assays. We also thank Dr Vliers, Paediatric Cardiology, University of Louvain, and Dr de Barsy, I. C. P., University of Louvain, who permitted the conjunctival biopsy of case 2 .

This work was supported by an FGWO grant (3.0033.77) and an FRSM grant (3.4543.76).

\section{References}

Adachi, M., Schneck, L., and Volk, B. W. (1974). Ultrastructural studies of eight cases of fetal Tay-Sachs disease. Laboratory Investigation, 30, 102.

Baudhuin, P., Hers, H. G., and Loeb, H. (1964). An electron microscopic and biochemical study of type II glycogenosis. Laboratory Investigation, 13, 1139. 
Engel, A. G., Gomez, M. R., Seybold, M. E., and Lambert, E. H. (1973). The spectrum and diagnosis of acid maltase deficiency. Neurology (Minneapolis), 23, 95.

Hers, H. G. (1963). Alpha-glucosidase deficiency in generalized glycogen storage disease (Pompe's disease). Biochemical Journal, 86, 11.

Hers, H. G., and de Barsy, T. (1973). Type II glycogenosis (acid maltase deficiency). In Lysosomes and storage diseases, pp. 197-216. Edited by H. G. Hers and F. Van Hoof. Academic Press: New York.

Howes, E. L., Wood, I. S., Golbus, M., and Hogan, M. L. (1975). Ocular pathology of infantile Niemann-Pick disease. Study of a fetus of 23 weeks' gestation. Archives of Ophthalmology, 93, 494.

Hug, G., Soukup, S., Schubert, W. K., and McLain, C. R. (1973). Prenatal diagnosis and fetal pathology of infantile glycogenosis type II. Pediatric Research, 7, 389.

Libert, J., Toussaint, D., and Guiselings, R. (1975). Ocular findings in Niemann-Pick disease. American Journal of Ophthalmology, 80, 991.

Martin, J.-J., de Barsy, T., De Schrijver, F., Leroy, J. G., and Palladini, G. (1976). Acid maltase deficiency (type II glycogenosis). Morphological and biochemical study of a childhood phenotype. Journal of the Neurological Sciences, 30, 155.

Martin, J.-J., de Barsy, T., Van Hoof, F., and Palladini, G.
(1973). Pompe's disease: an inborn lysosomal disorder with storage of glycogen. A study of brain and striated muscle. Acta Neuropathologica, 23, 229.

Nadler, H. L., and Messina, A. M. (1969). In utero detection of type II glycogenosis (Pompe's disease). Lancet, 2, 1277.

Reynolds, E. S. (1963). The use of lead citrate at high pH as an electron opaque stain in electron microscopy, Journal of Cell Biology, 17, 208.

Schaub, J., Osang, M., von Bassewitz, D. B., Grote, W., Terinde, R., Lombeck, I., and Bremer, H. J. (1974). Pränatale Diagnose einer Glycogenose Typ II (Pompe) mit nachfolgender Interruptio. Deutsche Medizinische Wochenschrift, 99, 2219.

Schneider, E. L., Ellis, W. G., Brady, R. O., McCulloch, J. R., and Epstein, C. J. (1972). Prenatal Niemann-Pick disease: biochemical and histologic examination of a 19-gestational week fetus. Pediatric Research, 6, 720.

Smith, R. S., and Reinecke, R. D. (1972). Electron microscopy of ocular muscle in type II glycogenosis (Pompe's disease). American Journal of Ophthalmology, 73, 965.

Thiéry, J.-P. (1967). Mise en évidence des polysaccharides sur coupes fines en microscopie électronique. Journal de Microscopie, 6, 987.

Toussaint, D., and Danis, P. (1965). Ocular histopathology in generalized glycogenosis (Pompe's disease). Archives of Ophthalmology, 73, 342. 